\title{
The efficiency of magnetic hyperthermia and in vivo histocompatibility for human-like collagen protein-coated magnetic nanoparticles
}

This article was published in the following Dove Press journal:

International Journal of Nanomedicine

23 March 2016

Number of times this article has been viewed

\author{
Le Chang' \\ Xiao Li Liu',2 \\ Dai Di Fan' \\ Yu Qing Miao' \\ Huan Zhang' \\ He Ping Ma' \\ Qiu Ying Liu' \\ Pei Ma' \\ Wei Ming Xue' \\ Yan E Luo' \\ Hai Ming Fan ${ }^{1,3}$ \\ 'Shaanxi Key Laboratory of \\ Degradable Biomedical Materials, \\ School of Chemical Engineering, \\ Northwest University, Xi'an, \\ Shaanxi, People's Republic of China; \\ ${ }^{2}$ Department of Materials Science and \\ Engineering, Faculty of Engineering, \\ National University of Singapore, \\ Singapore; ${ }^{3}$ Key Laboratory of \\ Synthetic and Natural Functional \\ Molecule Chemistry of the Ministry \\ of Education, College of Chemistry \\ and Materials Science, Northwest \\ University, Xi'an, Shaanxi, People's \\ Republic of China
}

Correspondence: Xiao Li Liu Department of Materials Science and Engineering, Faculty of Engineering, National University of Singapore,

7 Engineering Drive I, I I7574, Singapore

Tel +65 65I67896

Email liuxiaoli I9870108@I26.com

Dai Di Fan

Shaanxi Key Laboratory of Degradable

Biomedical Materials, School of Chemical

Engineering, Northwest University,

Xi'an 710069, Shaanxi, People's

Republic of China

$\mathrm{Tel} / \mathrm{fax}+862988305 \mathrm{II} 8$

Email fandaidi@nwu.edu.cn

\begin{abstract}
Magnetic hyperthermia is a promising technique for the minimally invasive elimination of solid tumors. In this study, uniform magnetite nanoparticles (MNPs) with different particle sizes were used as a model system to investigate the size and surface effects of human-like collagen protein-coated MNPs (HLC-MNPs) on specific absorption rate and biocompatibility. It was found that these HLC-MNPs possess rapid heating capacity upon alternating magnetic field exposure compared to that of MNPs without HLC coating, irrespective of the size of MNPs. The significant enhancement of specific absorption rate is favorable for larger sized nanoparticles. Such behavior is attributed to the reduced aggregation and increased stability of the HLC-MNPs. By coating HLC on the surface of certain sized MNPs, a significant increase in cell viability (up to 2.5-fold) can be achieved. After subcutaneous injection of HLC-MNPs into the back of Kunming mice, it was observed that the inflammatory reaction hardly occurred in the injection site. However, there was a significant presence of phagocytes and endocytosis after the injection of nonconjugated counterparts. The overall strategy to fabricate HLC-MNPs can serve as a general guideline to address the current challenges in clinical magnetic hyperthermia, improved biocompatibility, and enhanced heating characteristics through protein coating.
\end{abstract}

Keywords: $\mathrm{Fe}_{3} \mathrm{O}_{4}$ nanoparticles, human-like collagen protein, SAR value, biocompatibility

\section{Introduction}

Magnetic hyperthermia using nanoparticles (NPs) is one of the cancer treatment techniques and has received approval from the German Federal Institute for Drug and Medical Devices to start the postmarketing study in glioblastoma with NanoTherm ${ }^{\circledR}$ therapy. ${ }^{1}$ Such a study is based on the concept that cancer cells are more sensitive than normal cells to heat. Compared with conventional surgical treatment or thermal ablation therapies (such as laser, focused ultrasound, radiofrequency, and microwave), the outstanding advantages of magnetic hyperthermia include 1) the minimum invasion, 2) the separated energy source from the heating source, and 3) the deep lesion penetration in the body. ${ }^{2-10}$ As such, these advantages allow magnetic hyperthermia to be prevalent in cancer treatment. In realizing magnetic hyperthermia technique, magnetic NPs are an essential prerequisite. In general, the magnetic NPs are embedded within the tumor site and are subsequently subjected to an external alternating magnetic field (AMF). Subsequently, the magnetic NPs will allow an efficient transfer of external energy into heat dissipation into the surrounding environment; when the temperature of the tumor site is increased to $42^{\circ} \mathrm{C}-46^{\circ} \mathrm{C}$, cancer cell apoptosis will take place. ${ }^{11-13}$ Currently, superparamagnetic iron oxide (SPIO) NPs have been widely 
investigated as magnetic hyperthermia agents because of the formation of stable suspension and their highly active surface for a wide range of biofunctionalization. However, the intrinsic weak magnetic property of small-sized SPIOs results in low performance of magnetic hyperthermia, limiting their potential for magnetic hyperthermia-based cancer treatment. Moreover, the effective design strategy of SPIOs to improve the overall specific absorption rate (SAR) is still confined because of the saturation magnetization $\left(M_{\mathrm{s}}\right)$ limit for SPIOs. Therefore, in most cases, high SPIO concentrations or high magnetic field strength is being employed to kill cancer cells effectively. The associated high toxicity due to high SPIO concentrations as well as the nonspecific tissue heating due to high magnetic field exposure was the drawback from such strategy.

The general requirements of magnetic hyperthermia agents are mainly related to their $M_{\mathrm{s}}$, surface coating, and size. ${ }^{14-19}$ These parameters strongly affect both the magnetic behavior of the particles and their stability, biocompatibility, and biodistribution. Ideally, a magnetic hyperthermia agent should have active targeting capabilities to allow their accumulation in the target tumor/cancer cells. Recently, significant attention has been drawn in the conjugation of protein (eg, antibodies or cell-specific ligands) with magnetic NPs for the purpose of inducing localized magnetic hyperthermia. For example, by conjugating the epidermal growth factor with magnetic NPs, the magnetic NPs were observed to effectively target overexpressed epidermal growth factor receptor cells, resulting in a significant reduction in cell viability in a thermal heat dose-dependent manner. ${ }^{20}$ However, the enhanced cancer cell uptake by the conjugation of specific ligands with a magnetic hyperthermia agent usually leads to reduced SAR value due to the decrease in the overall effective $M_{\mathrm{s}}$. Therefore, protein coating is capable of improving biocompatibility and enhancing cellular uptake at the expense of decreasing the effective SAR value. Recent work on bovine serum albumin (BSA)-coated SPIOs indicated a contradicting trend to the aforementioned phenomenon, in which protein coating was capable of simultaneously inducing rapid heating capability for thermal therapy and possessing low toxicity characteristic. ${ }^{21}$ Nevertheless, BSA cannot be directly used in clinical applications as the heterogeneous protein will induce the adverse immune response of patients. In addition to this, the improvement of SPIO SAR by additional protein coating is still limited because of its inherent intrinsic weak magnetic property (low $M_{\mathrm{s}}$ ). It is also unclear whether protein will have a significant role in improving SAR and biocompatibility, especially for larger sized magnetic NPs. The effect of size and surface protein on SAR and biocompatibility for a magnetic hyperthermia agent should be thoroughly investigated to provide a general guideline in designing a perfect magnetic hyperthermia agent in clinical applications.

In this study, highly monodisperse and uniform magnetite NPs (MNPs) with different sizes have been prepared and the size and surface effects of human-like collagen protein-coated MNPs (HLC-MNPs) on SAR and biotoxicity have been investigated. The narrow size distribution of MNPs with different sizes synthesized by high-temperature thermal decomposition method is vital for our study. HLC is employed in this work for conjugation with magnetic NPs because of its low immunogenicity in addition to its excellent biocompatibility, being easily dissolvable in aqueous solutions, ease of handling, and versatile functionality. ${ }^{22,23} \mathrm{HLC}$ is conjugated on MNPs via covalent bonding by 1-ethyl-3(3-dimethylaminopropyl)carbodiimidehydrochloride/Nhydroxysuccinimide (EDC/NHS) carbodiimide chemistry. The sizes of $\mathrm{Fe}_{3} \mathrm{O}_{4}$ cores range from $8 \mathrm{~nm}$ to $24 \mathrm{~nm}$ in diameter. The magnetic properties of HLC-coated MNPs and the colloidal stability of the dispersions are characterized. The dependence of the measured SAR and biocompatibility on the HLC for different sized MNPs is systematically investigated. The goal of this study is to provide a general strategy of fabricating a new biocompatible system, which exhibits better heating characteristics for magnetic hyperthermia. More importantly, this strategy of fabricating HLC-MNPs can serve as a general guideline to address the current challenges in clinical magnetic hyperthermia and improved biocompatibility, and enhanced heating characteristics could be achieved through coating protein.

\section{Experimental Materials}

Absolute ethanol and hexane (J.T. Baker, 99.0\%; Thermo Fisher Scientific, Waltham, MA, USA; 99.99\%) were used as received. Benzyl ether (99\%), oleic acid (90\%), iron (III) acetylacetonate $(\mathrm{Fe}(\mathrm{acac}) ; 97.9 \%)$, acetonitrile ( $\geq 99.0 \%)$, and sodium periodate ( $\geq 99.8 \%$ ) were purchased from SigmaAldrich Co. (St Louis, MO, USA). Ethyl acetate (99.5\%) was purchased from Fluka (St Louis, MO, USA).

\section{Preparation of highly monodispersed MNPs}

$\mathrm{Fe}_{3} \mathrm{O}_{4}$ NPs were prepared by thermal decomposition method with slight modification. ${ }^{24,25}$ Briefly, Fe(acac) 3 (12 mmol), oleic acid (40 $\mathrm{mmol})$, and benzyl ether $(50 \mathrm{~mL})$ were mixed 
and magnetically stirred under a flow of nitrogen. The mixture was heated to $165^{\circ} \mathrm{C}$ for 30 minutes and then heated to reflux $\left(280^{\circ} \mathrm{C}\right)$ under a nitrogen atmosphere for another 30 minutes. The black-brown mixture was cooled to room temperature naturally. Under ambient conditions, ethanol $(50 \mathrm{~mL})$ was then added to the mixture. The product of $17 \mathrm{~nm}$ MNPs was separated via centrifugation and redispersed into hexane $(10 \mathrm{~mL})$. By varying the concentration of precursors, MNPs with different sizes were successfully synthesized.

\section{Coating HLC on MNPs}

The as-synthesized $\mathrm{Fe}_{3} \mathrm{O}_{4}$ NPs were hydrophobic in nature due to the oleic acid capping. The $\mathrm{Fe}_{3} \mathrm{O}_{4}$ NPs have to be converted into hydrophilic phase prior to their in vitro and in vivo applications. By oxidation of oleic acid coated on the surface of $\mathrm{Fe}_{3} \mathrm{O}_{4}$ NPs, the obtained hydrophilic $\mathrm{Fe}_{3} \mathrm{O}_{4}$ NPs are easily coated with HLC because of the produced azelaic and pelargonic acids with carboxyl group. First, the hydrophobic $\mathrm{Fe}_{3} \mathrm{O}_{4}$ NPs $(20 \mathrm{mg}$ ) dispersed in hexane were added into a $2 \mathrm{~mL}$ mixture of ethyl acetate and acetonitrile at $1: 1$ volume ratio. Then, the sodium periodate aqueous solution $(15 \mathrm{mg} / \mathrm{mL})$ was added with vigorous stirring. After 2 hours, the homogeneous reactant mixture became two separated layers: the top hexane layer was colorless and discarded, and the bottom aqueous layer was collected and magnetically separated. After washing with ethanol and distilled water for several times, the obtained $\mathrm{Fe}_{3} \mathrm{O}_{4}$ NPs were redispersed in water.

Coating of HLC on the surface of hydrophilic $\mathrm{Fe}_{3} \mathrm{O}_{4} \mathrm{NPs}$ was performed by using standard EDC/NHS. Briefly, $26 \mathrm{mM}$ EDC and $10 \mathrm{mM}$ NHS were prepared in 2-( $N$-morpholino $)$ ethane sulfonic acid buffer. Then, $200 \mu \mathrm{L}$ of EDC/NHS/2( $N$-morpholino) ethane sulfonic acid mixture was added to $1 \mathrm{~mL} \mathrm{HLC}(2 \mathrm{mg} / \mathrm{mL})$ to activate the amino group, and $2 \mathrm{~mL}$ of hydrophilic $\mathrm{Fe}_{3} \mathrm{O}_{4}$ NPs were dispersed in $1 \times$ phosphatebuffered saline $(0.1 \mathrm{mg} / \mathrm{mL})$. The $\mathrm{pH}$ was maintained at 7.2-7.4. Both the solutions were then mixed and left in the shaker overnight at room temperature. The reaction was terminated, and the product was washed.

\section{Characterization}

X-ray powder diffraction (XRD) patterns of the $\mathrm{Fe}_{3} \mathrm{O}_{4} \mathrm{NPs}$ with different sizes were collected on a Bruker D8 Advanced Diffractometer System equipped with $\mathrm{Cu} / \mathrm{K}$ radiation in the $2 \theta$ range from $20^{\circ}$ to $70^{\circ}(\lambda=1.5418 \AA$ ). The size and morphology of as-synthesized $\mathrm{Fe}_{3} \mathrm{O}_{4}$ NPs were characterized using a JEOL 100CX transmission electron microscope (TEM) operating at $200 \mathrm{kV}$. The mean particle size was obtained from digitalized TEM images by counting $>100$ particles. Dynamic light scattering measurements were performed in a Malvern Zetasizer Nano-ZS device to determine the hydrodynamic size of $\mathrm{Fe}_{3} \mathrm{O}_{4}$ NPs before and after coating HLC in a colloidal suspension. The zeta potential was measured at $\mathrm{pH}=7$ at $25^{\circ} \mathrm{C}$. Ultraviolet (UV)-visible absorption spectra were taken using a Shimadzu UV-1601 UV-visible spectrophotometer. Magnetic properties of the samples were characterized by a LakeShore Model 7407 vibrating sample magnetometer. The mass of HLC adsorbed on the particles was determined using thermogravimetric analysis (TGA) SDTQ600 instrument.

\section{Magnetic hyperthermia}

$\mathrm{Fe}_{3} \mathrm{O}_{4}$ NPs before and after coating HLC were dispersed in water. Plastic bottles containing $2 \mathrm{~mL}$ samples thermally insulated with ceramic wool were placed within a watercooled copper coil driven by an Inductelec A.C. generator (SPG-10AB-II; Shenzhen Magtech Company Limited, Shenzhen, People's Republic of China). The temperature raise of the sample with respect to the time of exposure of the sample to an AMF at amplitude of 560 Oe and frequency of $360 \mathrm{kHz}$ was investigated. A LuxtronMD600 fiber optic thermometry unit connected to a computer was used to measure the sample's temperature. The SAR of samples was calculated from the following equation: ${ }^{18,19}$

$$
\mathrm{SAR}=C \frac{\Delta T}{\Delta t} \frac{1}{m_{\mathrm{Fe}}}
$$

where $C$ is the specific heat of the medium $\left(C_{\text {water }}=4.18 \mathrm{Jg}^{-1} \mathrm{C}^{-1}\right)$, $\Delta T / \Delta t$ is the maximum slope of the time-dependent temperature curve, and $m_{\mathrm{Fe}}$ is the weight fraction of the magnetic element in the sample.

\section{In vitro cytotoxicity assay}

Baby hamster kidney BHK-21 cells were purchased from American Type Culture Collection (ATCC, Manassas, VA, USA). In a $\mathrm{CO}_{2}(5 \%)$ incubator at $37^{\circ} \mathrm{C}, \mathrm{BHK}-21$ cells were cultured in RPMI Medium 1640 (1640) and Dulbecco's Modified Eagle's Medium (ATCC ${ }^{\circledR} 30-2002^{\mathrm{TM}}$ ) with 10\% $(\mathrm{v} / \mathrm{v})$ fetal bovine serum. Cells in log-growing phase were used for all experiments. BHK-21 cells were seeded in 96-well plate at the density of $1 \times 10^{4}$ viable cells/well with $100 \mu \mathrm{L} /$ well $(\mathrm{n}=6)$ using RPMI containing $10 \%$ fetal bovine serum and then cultured in the incubator for 24 hours in order to make cells attached to the bottom of the culture plate. The medium was removed and replaced with fresh medium. To each well, $100 \mu \mathrm{L} \mathrm{Fe}_{3} \mathrm{O}_{4} \mathrm{NP}$ suspensions before and after 
coating HLC at concentrations of $12.5 \mu \mathrm{g} / \mathrm{mL}, 25 \mu \mathrm{g} / \mathrm{mL}$, $50 \mu \mathrm{g} / \mathrm{mL}$, and $100 \mu \mathrm{g} / \mathrm{mL}$ Fe were added. After incubation for 1 day, 2 days, and 3 days, the dishes were analyzed for the relative growth rate with a Cell Counting Kit-8 (SigmaAldrich Co.) following the manufacturer's manual. Untreated wells were used as control.

\section{In vivo histocompatibility evaluation Injection of samples}

Assessment of the in vivo biocompatibility of samples was performed by injecting the samples into male Kunming mice (20-25 g). Before injection, $\mathrm{Fe}_{3} \mathrm{O}_{4} \mathrm{NPs}$ before and after coating HLC are dispersed into the agarose gel. After shaving and disinfection, $0.5 \mathrm{~mL}$ of the sample was injected subcutaneously into the back of the Kunming mice. Before treatment, all the animals were quarantined for a week, allowing free access to food and water but not any antibiotics. All the in vivo experiments were conducted according to the guidelines of Animal Care and Use and approved by the Institutional Animal Care and Use Committee of the Northwest University.

\section{TEM analysis}

Kunming mice were divided into three groups: the negative control group was injected with pure agarose gel, while the others were injected with $\mathrm{Fe}_{3} \mathrm{O}_{4}$ NPs and HLC Fe $\mathrm{O}_{4}$ NPs. The injected tissue was removed after 7 days postsurgery. Tissue blocks of $1 \mathrm{~mm}^{3}$ were fixed immediately with $2.5 \%$ phosphate-buffered glutaraldehyde for 2 hours, rinsed with $0.1 \mathrm{M}$ phosphate-buffered saline for 30 minutes, postfixed in $1 \%$ osmium tetroxide for 2 hours, and finally rinsed for 10 minutes using a $0.1 \mathrm{M}$ phosphate buffer. The samples were then dehydrated using an ethanol series. Finally, the samples were embedded in Epon 812. Semithin sections (1-2 mm) were cut and stained with methylthioninium chloride to select appropriate areas for observation. Ultrathin sections (50-70 nm) were stained with 4\% uranyl acetate and $0.5 \%$ lead citrate and observed under a TEM (Hitachi H-600; Hitachi Ltd., Tokyo, Japan).

\section{Results and discussion Characterization of the as-synthesized MNPs}

Different sizes ( $8 \mathrm{~nm}, 17 \mathrm{~nm}$, and $24 \mathrm{~nm}$ ) of highly monodispersed $\mathrm{Fe}_{3} \mathrm{O}_{4}$ NPs were synthesized by high-temperature thermal decomposition method in nonpolar solvent. Using this approach ensures high quality of the as-prepared MNPs. The size of the as-prepared $\mathrm{Fe}_{3} \mathrm{O}_{4}$ NPs was simply tuned by controlling the reaction concentration of producers and

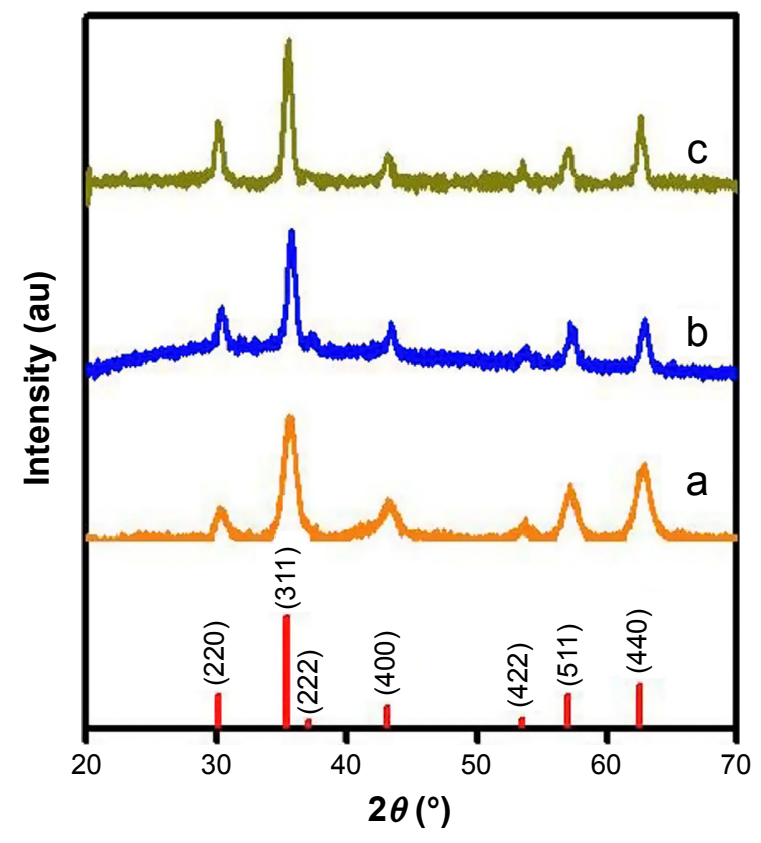

Figure I XRD patterns of $\mathrm{Fe}_{3} \mathrm{O}_{4}$ NPs: (a) $8 \mathrm{~nm}$, (b) $17 \mathrm{~nm}$, and (c) $24 \mathrm{~nm}$. Abbreviations: NPs, nanoparticles; XRD, X-ray powder diffraction.

growth temperature. XRD patterns from Figure 1 show that the $\mathrm{Fe}_{3} \mathrm{O}_{4}$ NPs are free of impurities. The diffraction peaks can be exclusively indexed as cubic inverse spinel $\mathrm{Fe}_{3} \mathrm{O}_{4}$ Joint Committee on Powder Diffraction Standards (JCPDS no 19-0629), corresponding to (220), (311), (222), (400), (422), (511), and (440). As the particle size increased, the XRD characteristic peaks became narrower.

The size and shape of the monodisperse MNPs were confirmed by TEM images (Figure $2 \mathrm{~A}-\mathrm{C}$ ). From the TEM images, it is clearly observed that the morphology of all sized NPs is uniform spheres. In addition, the corresponding TEM size histograms shown in Figure 2D-F reveal the narrow size distribution of $\mathrm{Fe}_{3} \mathrm{O}_{4} \mathrm{NPs}$, and the measured average sizes are $8.4 \mathrm{~nm}, 17.1 \mathrm{~nm}$, and $24.4 \mathrm{~nm}$, respectively, which is identical to calculated size from the XRD data by Scherrer equation. Their good crystallization, uniform size, and narrow size distribution could serve as a model system for determining the size and surface effect in magnetic hyperthermia measurements.

The as-prepared MNPs are hydrophobic, and a surface modification should be carried out to disperse them in an aqueous medium. To investigate the effect of HLC on the performance of magnetic hyperthermia, HLC is coated on the surface of $\mathrm{Fe}_{3} \mathrm{O}_{4}$ NPs by oleic acid oxidation method and subsequent EDC/NHS carbodiimide chemistry. Figure 3 shows the zeta potential of different sized $\mathrm{Fe}_{3} \mathrm{O}_{4}$ NPs after coating with different amounts of HLC at neutral $\mathrm{pH}$ value $(\mathrm{pH}=7)$. Uncoated MNPs exhibit a zeta potential of approximately $-21.4 \mathrm{mV}$, approximately $-25.1 \mathrm{mV}$, and approximately $-21.1 \mathrm{mV}$ for 
A
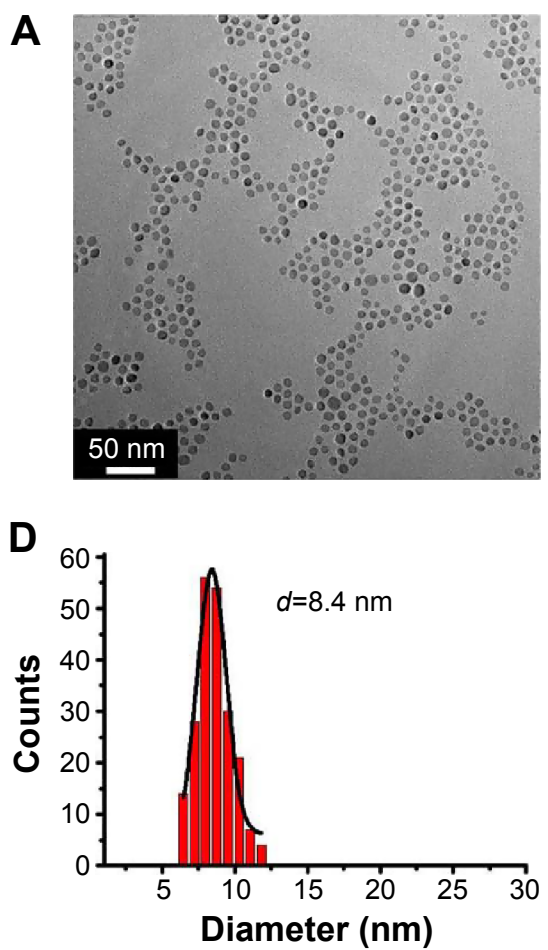

B

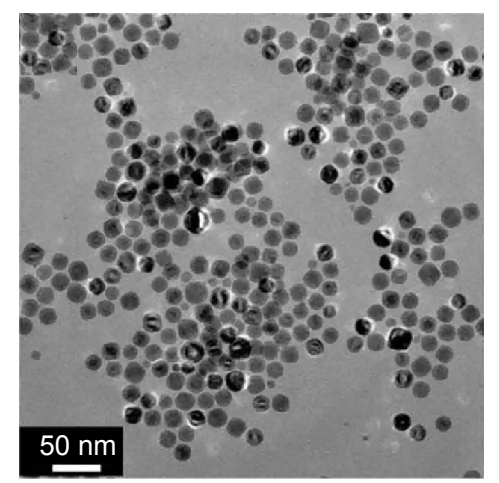

E

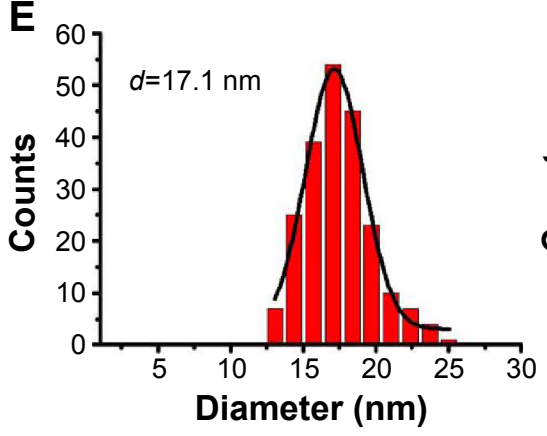

C

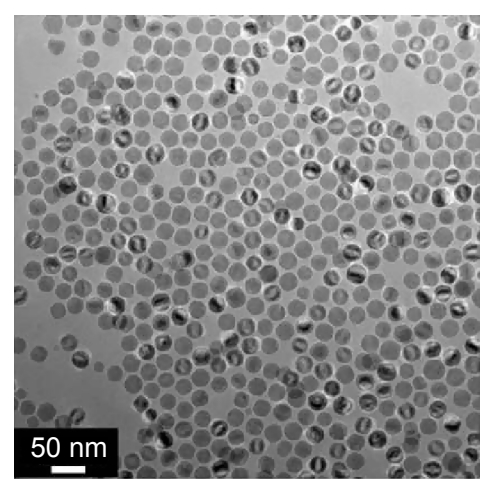

$\mathbf{F}$

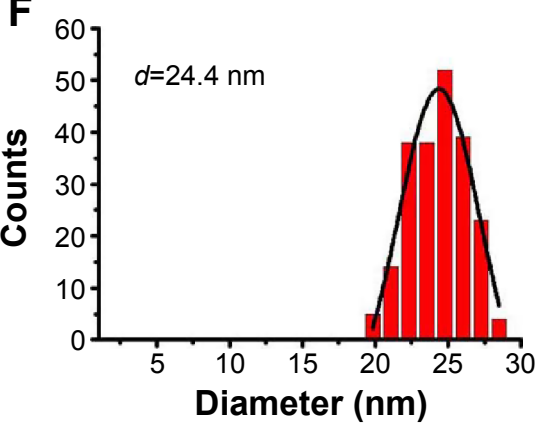

Figure 2 TEM images of $\mathrm{Fe}_{3} \mathrm{O}_{4}$ NPs with different sizes: (A) $8 \mathrm{~nm}$; (B) $17 \mathrm{~nm}$; (C) $24 \mathrm{~nm}$; and (D-F) the corresponding size distributions of three samples. Abbreviations: NPs, nanoparticles; TEM, transmission electron microscope.

$8 \mathrm{~nm}, 17 \mathrm{~nm}$, and $24 \mathrm{~nm}$ samples, respectively. These negative surface charges were due to the dissociation of the carboxyl groups at the chain end. After coating HLC for certain sized MNPs, the zeta potential decreases correspondingly, compared with the sample before coating HLC. Moreover, the zeta potential decreased with increasing concentration
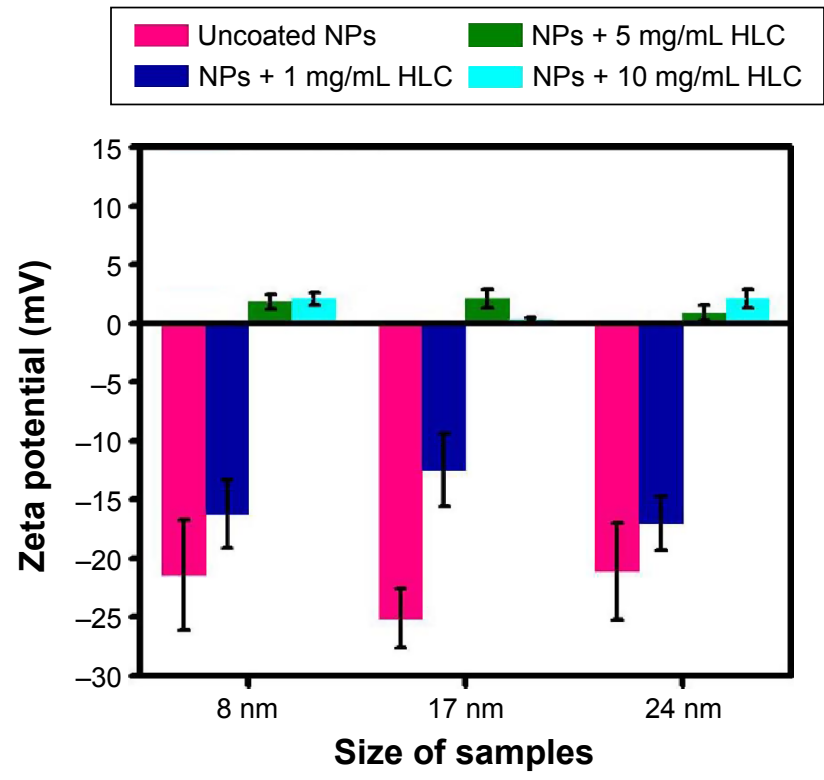

Figure 3 Surface charges (zeta potential) of the corresponding modified MNPs at neutral $\mathrm{pH}$ value $(\mathrm{pH}=7)$.

Abbreviations: HLC, human-like collagen; MNPs, magnetite NPs; NPs, nanoparticles. of HLC conjugated on the surface of MNPs. The decreased zeta potential of HLC-MNPs results from the positive charge of HLC in water. The decrease in surface charge after conjugating with HLC verified that HLC was conjugated with the surface of MNPs, as the cation HLC decreased the zeta potential of the system. In terms of electrostatic repulsion for conferring colloidal stability, the concentration of $1 \mathrm{mg} / \mathrm{mL}$ HLC for coating MNPs is favored.

After optimizing the concentration of HLC coated on the surface of $\mathrm{Fe}_{3} \mathrm{O}_{4} \mathrm{NPs}$, UV-visible and dynamic light scattering experiments were conducted to further confirm that HLC has been coated on the surface. As shown in Figure 4A, there is no peak observed in MNPs without HLC. The wellknown maximum absorbance peak is at $280 \mathrm{~nm}$ for the natural type I collagen solution, which is due to the $\pi \rightarrow \pi^{*}$ transition of the aromatic amino acid residues. ${ }^{26,27}$ The characteristic peak of HLC is prominent at $220 \mathrm{~nm}$ (Figure 4A) because of $n \rightarrow \pi^{*}$ transition of $\mathrm{C}=\mathrm{O}$ in the peptide bond, which is unique as to the natural type I collagen solution. This is due to the fact that the contents of aromatic amino acid residues were very low in HLC. Furthermore, HLC lacks tryptophan residue. ${ }^{28-30}$ The blueshift of the absorption peak verifies that the HLC was conjugated to the surface of MNPs. The disturbance in the polypeptide environment within the HLC due to the conjugation of the surface-modified MNP system is the reason behind the blueshift. 


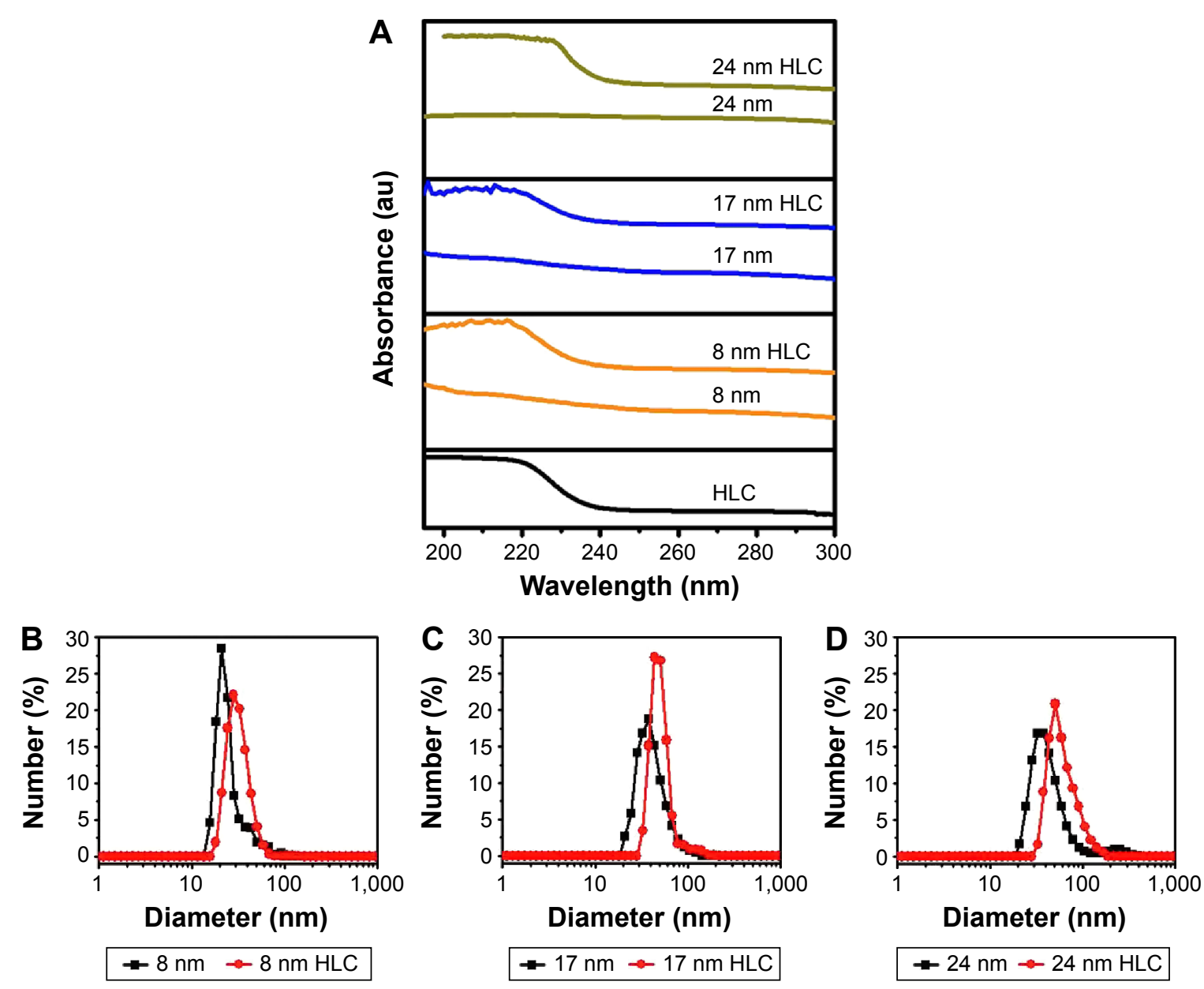

Figure 4 Surface coating chemistry of samples.

Notes: (A) UV-visible spectra of $\mathrm{HLC}$ and $\mathrm{HLC}$-coated $\mathrm{Fe}_{3} \mathrm{O}_{4}$ NPs. (B-D) Hydrodynamic diameters of the Fe $\mathrm{O}_{4} \mathrm{NPs}$ before and after coating $\mathrm{HLC}$ : (B) 8 nm, (C) I7 nm, and (D) $24 \mathrm{~nm}$.

Abbreviations: HLC, human-like collagen; NPs, nanoparticles; UV, ultraviolet; au, arbitrary unit.

Figure 4B-D shows the hydrodynamic radius of the different sized MNPs before and after coating HLC, respectively. After coating HLC, the average hydrodynamic radius is larger than that of bare samples without coating HLC. The average hydrodynamic radii of $8 \mathrm{~nm}$ HLC, $17 \mathrm{~nm}$ HLC, and $24 \mathrm{~nm}$ HLC are $32.2 \mathrm{~nm}, 51.8 \mathrm{~nm}$, and $84.4 \mathrm{~nm}$, respectively.

The magnetization properties of MNPs are shown in Figure 5A-C. The $M_{\mathrm{s}}$ value of $8 \mathrm{~nm}, 17 \mathrm{~nm}$, and $24 \mathrm{~nm}$ MNPs before coating HLC measured by vibrating sample magnetometer is $21 \mathrm{emu} / \mathrm{g}, 34 \mathrm{emu} / \mathrm{g}$, and $38 \mathrm{emu} / \mathrm{g}$, respectively. The $M_{\mathrm{s}}$ was decreased after coating HLC. The corresponding reduced $M_{\mathrm{s}}$ is $12 \mathrm{emu} / \mathrm{g}, 25 \mathrm{emu} / \mathrm{g}$, and $31 \mathrm{emu} / \mathrm{g}$, which is attributed to the reduced effective weight fraction of magnetic core, as confirmed by TGA in Figure 5D-F. Based on the TGA results, the weight percentages of HLC absorbed on MNPs are $\sim 26 \%, 15 \%$, and $10 \%$ for $8 \mathrm{~nm}, 17 \mathrm{~nm}$, and $24 \mathrm{~nm}$ MNPs, respectively. The higher $M_{\mathrm{s}}$ of larger sized MNPs allows it to be the preferred candidate for magnetic hyperthermia application.

\section{Enhancement of heating efficiency}

The heating efficiency of the MNPs and HLC-conjugated MNPs were studied by the magnetic hyperthermia experiments. Figure 6 shows the SAR value comparison of the MNPs before and after coating HLC. It is evident that the SAR value of $8 \mathrm{~nm} \mathrm{Fe}_{3} \mathrm{O}_{4} \mathrm{NPs}$ is $280 \mathrm{~W} / \mathrm{g}$ and that of $8 \mathrm{~nm} \mathrm{HLC}$ $\mathrm{Fe}_{3} \mathrm{O}_{4} \mathrm{NPs}$ is $440 \mathrm{~W} / \mathrm{g} ; 17 \mathrm{~nm} \mathrm{Fe} \mathrm{O}_{4}$ NPs is $710 \mathrm{~W} / \mathrm{g}$ and that of $17 \mathrm{~nm}-\mathrm{HLC} \mathrm{Fe}_{3} \mathrm{O}_{4} \mathrm{NPs}$ is $1,200 \mathrm{~W} / \mathrm{g} ; 24 \mathrm{~nm} \mathrm{Fe} \mathrm{O}_{4} \mathrm{NPs}$ is $732 \mathrm{~W} / \mathrm{g}$ and that of $24 \mathrm{~nm} \mathrm{HLC} \mathrm{Fe} \mathrm{O}_{4} \mathrm{NPs}$ is $1,410 \mathrm{~W} / \mathrm{g}$. It is observed that $\mathrm{Fe}_{3} \mathrm{O}_{4}$ NPs after coating HLC show better efficiency irrespective of the size of the particles. It was evident that larger size show higher SAR value due to their higher $M_{\mathrm{s}}$. It inherently implied that larger-sized $\mathrm{Fe}_{3} \mathrm{O}_{4}$ NPs were better suited candidates for improving the SAR value of the magnetic hyperthermia system, as compared with small-sized NPs.

The SAR values were observed to increase after coating HLC. Such trend indicates that HLC indeed improves the heating efficiency of the system. For the smaller $8 \mathrm{~nm}$ 


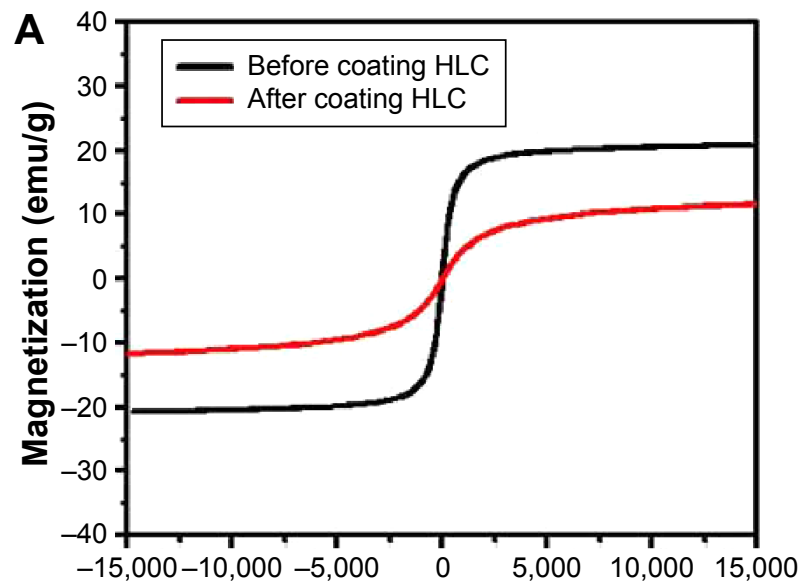

Field (Oe)

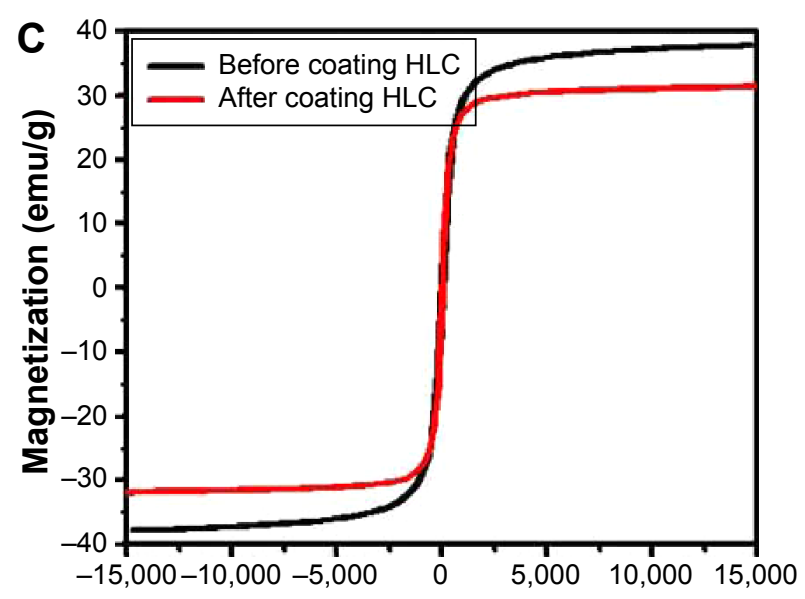

Field (Oe)

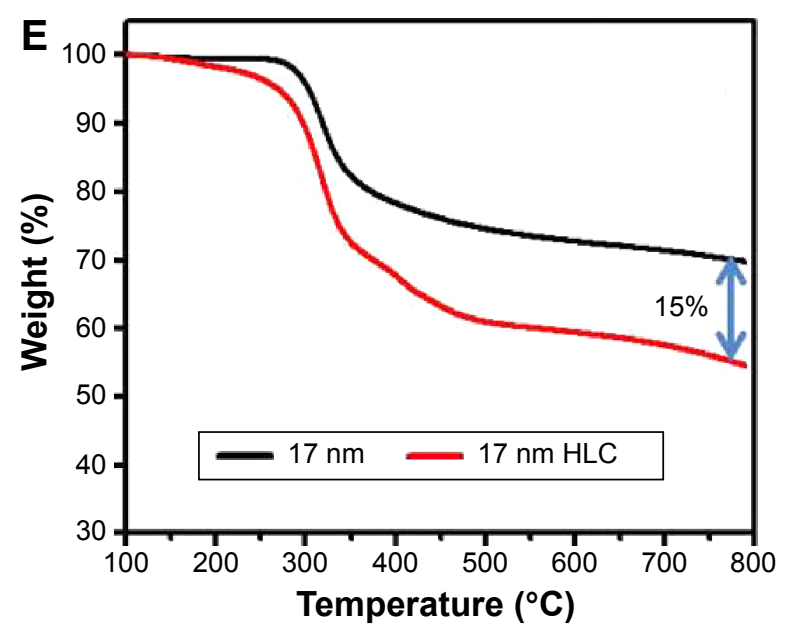

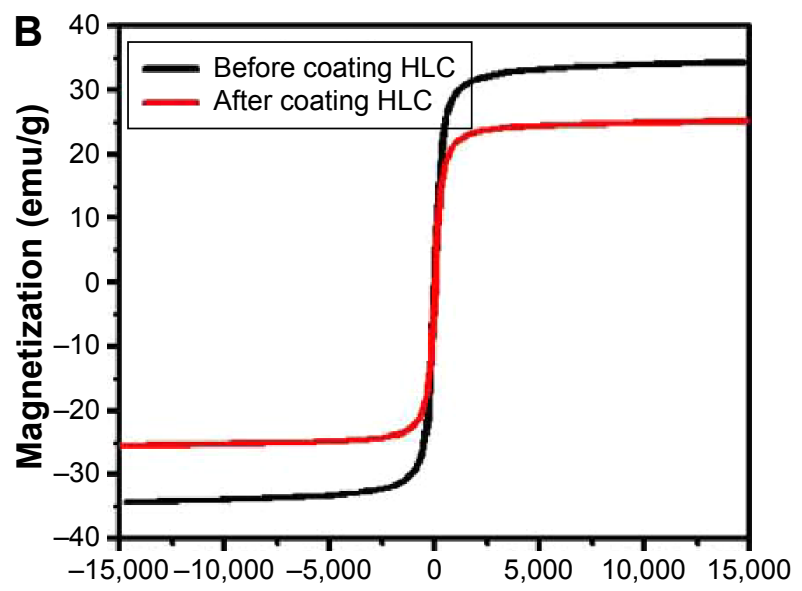

Field (Oe)
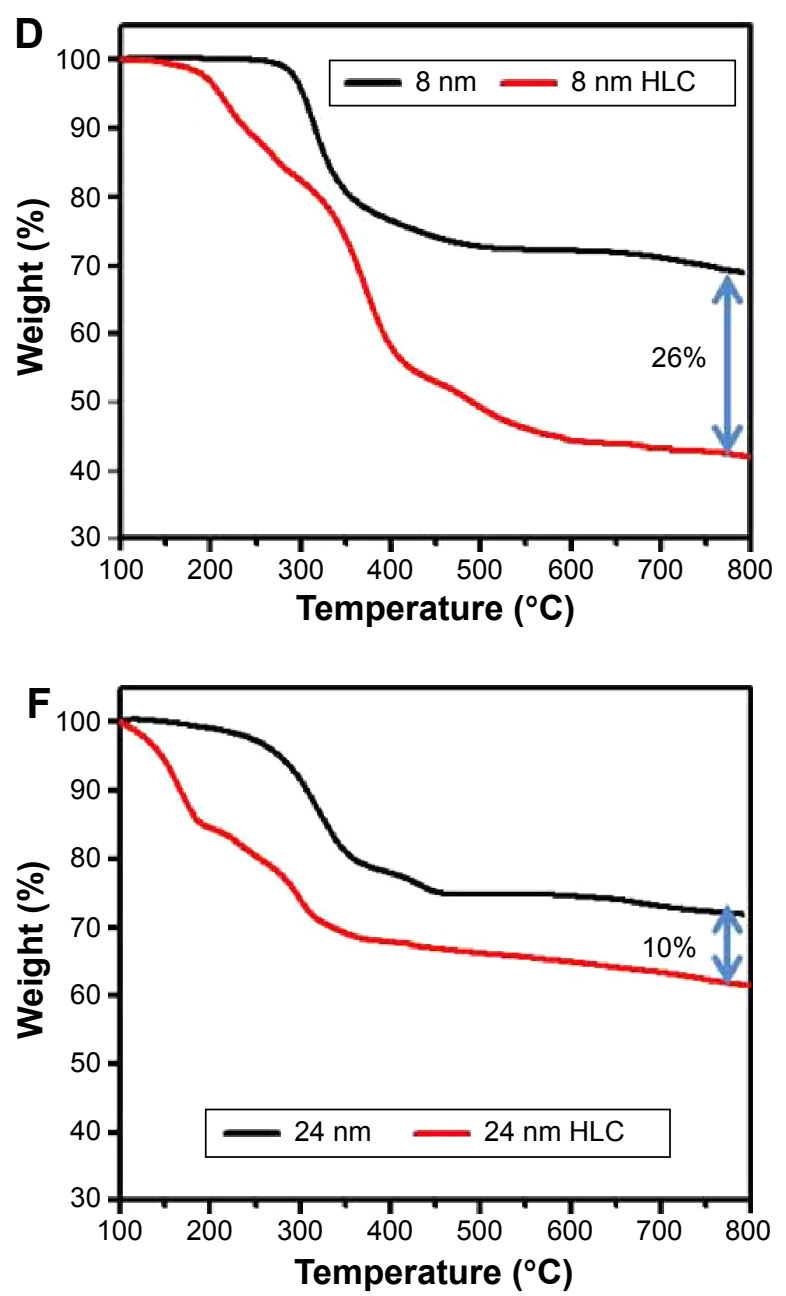

Figure 5 Magnetic hysteresis loops of $\mathrm{Fe}_{3} \mathrm{O}_{4}$ NPs before and after coating HLC with different sizes: (A) $8 \mathrm{~nm},(\mathbf{B}) 17 \mathrm{~nm}$, and (C) $24 \mathrm{~nm}$. TGA of the Fe $\mathrm{O}_{4}$ NPs before and after coating HLC: (D) $8 \mathrm{~nm}$, (E) $17 \mathrm{~nm}$, and (F) $24 \mathrm{~nm}$.

Abbreviations: HLC, human-like collagen; NPs, nanoparticles; TGA, thermogravimetric analysis.

samples, the SAR increases by only $57 \%$ after coating HLC. However, a significant increase in SAR (93\%) is observed for $24 \mathrm{~nm}$ samples with the same change. The variation of SAR for the $17 \mathrm{~nm}$ samples is $\sim 69 \%$. These data reveal that a significant enhancement of the SAR is favorable for larger
NPs at the same variation, ie, HLC coating is more effective in altering the SAR of larger particles than small particles.

In this study, the as-synthesized MNPs with $8 \mathrm{~nm}$, $17 \mathrm{~nm}$, and $24 \mathrm{~nm}$ sizes were either superparamagnetic or quasi-superparamagnetic. By using the classical formula of 


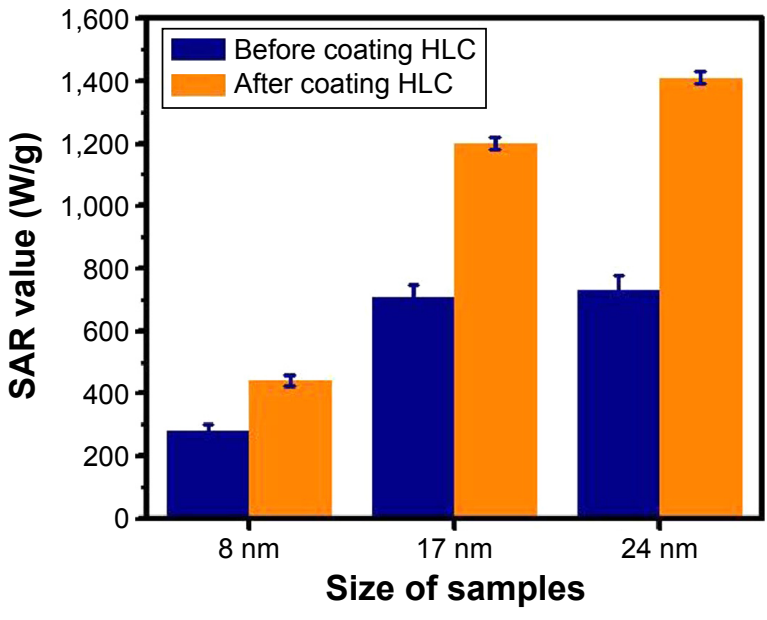

Figure 6 SAR value comparison of different sized $\mathrm{Fe}_{3} \mathrm{O}_{4} \mathrm{NPs}$ before and after coating HLC.

Abbreviations: HLC, human-like collagen; NP, nanoparticles; SAR, specific absorption rate.

$K V=25 k T$ (where $K$ is the magnetocrystalline anisotropy constant, $V$ is the volume of NP, $k$ the Boltzmann constant, and $T=300 \mathrm{~K}$ at room temperature), the calculated critical size for $\mathrm{Fe}_{3} \mathrm{O}_{4}$ NPs to exhibit superparamagnetic behavior is $\sim 20 \mathrm{~nm}$. For superparamagnetic or quasi-superparamagnetic NPs, there are two mechanisms that contribute to magnetic hyperthermia under an AMF, namely, 1) Néel and 2) Brownian relaxations. Heat generation through Néel relaxation is due to the magnetic moment reversing independently while the particle is immobile. On the other hand, Brownian relaxation is attributed to physical rotation of particles within their respective dispersing medium. The particle moved entirely and the magnetic moment is reversing along with the NP rotation. In principle, there are two main contributions from surface coating on the measured SAR. First, magnetic NPs after surface modification should have good dispersibility. It is well reported that aggregation of NPs decreases the SAR value significantly. ${ }^{19}$ Second, HLC is considered a biomacromolecule. The adsorption of biomacromolecules helps to prevent magnetic NPs from aggregating and to reduce the dipolar interaction. Then, time-variant magnetic field was discovered to be capable of inducing the anisotropic aggregates of magnetic NPs. Because the surface adsorption of HLC is capable to increase the repulsive interaction and weaken the magnetic interaction between the particles, the field-induced aggregation of magnetic NPs may be fully or partially inhibited after coating HLC. It has been reported in literature that isotropic clusters of BSA are formed under AMF. ${ }^{31}$ As such, HLC is able to behave similarly. After coating with HLC, the steric layer to stabilize the NPs might have possibly prevented the aggregation of magnetic NPs under AMF and form isotropic clusters. Prevention of aggregation by HLC conjugation might have thus enhanced the SAR value of the system.

\section{In vitro cytotoxicity}

Although magnetic NPs with high SAR play a paramount role in choosing the mediator for magnetic hyperthermia, other considerations should be fulfilled for suitable biomedical applications, such as specially targeting, biocompatibility, nontoxicity, ability to escape from the mononuclear phagocyte system, and low protein adsorption. The biocompatibility of a magnetic hyperthermia agent is a basic and an important factor for its practical applications. The Cell Counting Kit-8 assay is generally acknowledged as an effective method for testing the toxicity of magnetic hyperthermia agent. Incubation of BHK-21 cells with different concentrations $(12.5 \mu \mathrm{g} / \mathrm{mL}, 25 \mu \mathrm{g} / \mathrm{mL}, 50 \mu \mathrm{g} / \mathrm{mL}$, and $100 \mu \mathrm{g} / \mathrm{mL} \mathrm{Fe})$ of MNPs and HLC-MNPs with different sizes $(8 \mathrm{~nm}, 17 \mathrm{~nm}$, and $24 \mathrm{~nm}$ ) for 24 hours, 48 hours, and 72 hours is performed. As shown in Figure 7, there is no obvious change in cell viability for $24 \mathrm{~nm}$-sized sample before and after coating HLC after 24 hours, 48 hours, and 72 hours and almost no toxicity. In comparison with uncoated $17 \mathrm{~nm} \mathrm{Fe}_{3} \mathrm{O}_{4}$ NPs, $17 \mathrm{~nm}$ HLCMNPs have a significant increase in the cell viability at different incubation times. Without the $\mathrm{HLC}$ coating, $17 \mathrm{~nm} \mathrm{Fe}_{3} \mathrm{O}_{4}$ NPs have rapidly suppressed the cell viability with increasing incubating time, demonstrating time dependence. With the HLC coating, the cell viability can reach up to $100 \%$ at all concentration ranges tested, regardless of their incubation time. In addition, similar trend takes place for $8 \mathrm{~nm}$-sized samples in which the cell viability of the $8 \mathrm{~nm}$ HLC-MNPs is also higher than that in $8 \mathrm{~nm}$ MNPs. However, the extent of the improvement of biocompatibility after HLC coating was not notable. Thus, it can be concluded that HLC has greatly improved the cell viability and has favorable biocompatibility, especially for the $17 \mathrm{~nm}$-sized samples.

\section{In vivo histocompatibility evaluation}

To demonstrate the histocompatibility of HLC-coated MNPs as magnetic hyperthermia agent, in vivo histocompatibility evaluation was performed with $17 \mathrm{~nm}$-sized samples. During implantation, an interface created immediately between the materials and the blood, whereby proteins from the blood and tissue fluids adsorb nonspecifically to the material. Herein, both $17 \mathrm{~nm}$ MNPs and $17 \mathrm{~nm}$ HLC-MNPs were dispersed into agarose gel. The pure agarose gel was used as a control group. Subsequently, $0.5 \mathrm{~mL}$ hydrogels were injected into mice subcutaneously (Figure 8A). After 1 week, redness and edema appear in the injection site of $\mathrm{Fe}_{3} \mathrm{O}_{4} \mathrm{NPs}$ (Figure 8B), which indicate that inflammatory reaction had occurred. However, 

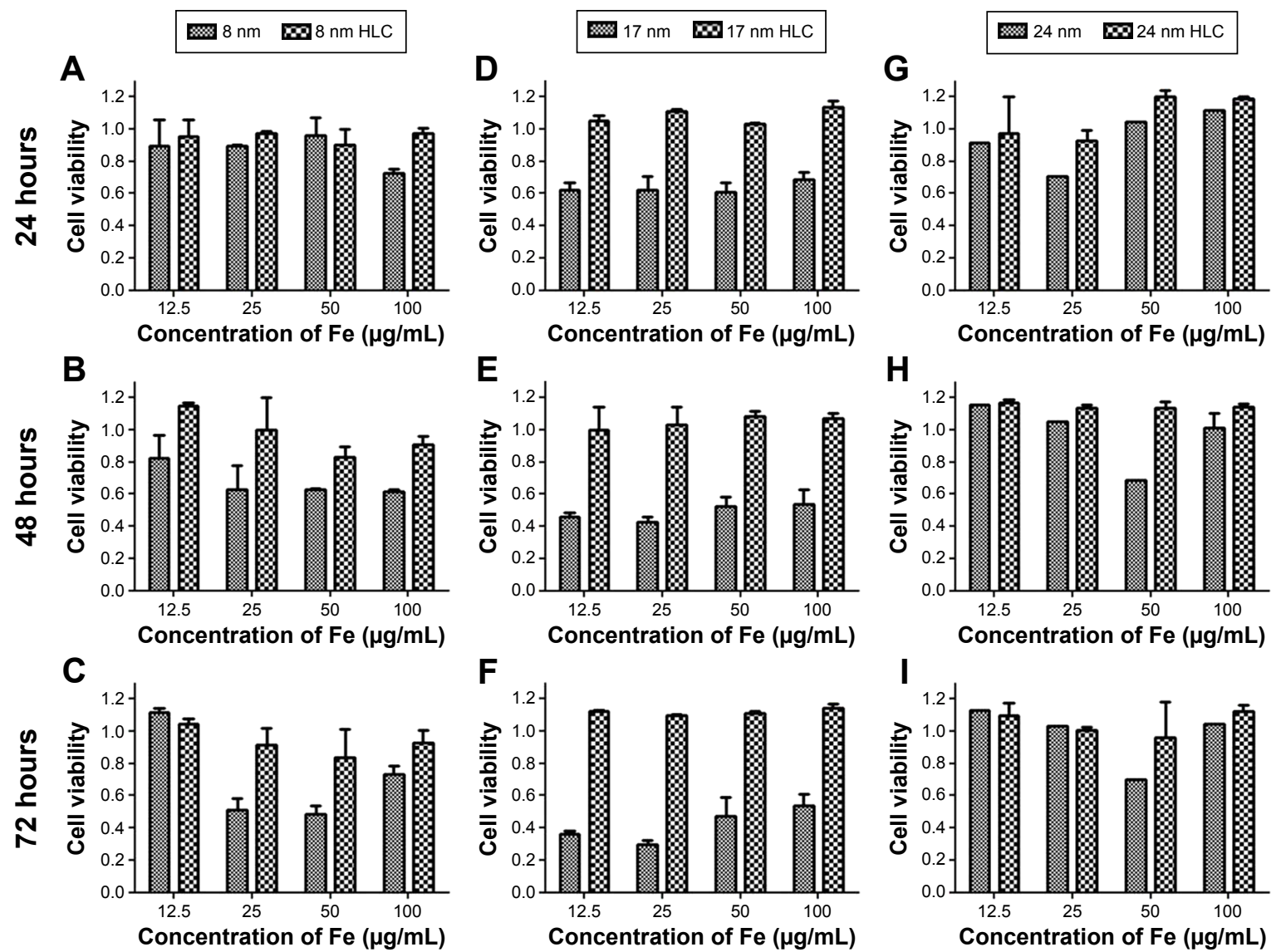

Figure 7 Cell viability on $8 \mathrm{~nm}(\mathbf{A}-\mathbf{C}), 17 \mathrm{~nm}(\mathbf{D}-\mathbf{F})$, and $24 \mathrm{~nm}(\mathbf{G}-\mathrm{I}) \mathrm{Fe}_{3} \mathrm{O}_{4} \mathrm{NPs}$ before and after coating HLC for 24 hours, 48 hours, and 72 hours, as determined by CCK-8 assay.

Abbreviations: CCK-8, Cell Counting Kit-8; HLC, human-like collagen; NPs, nanoparticles.

the injection site of $\mathrm{Fe}_{3} \mathrm{O}_{4} \mathrm{NPs}$ coated with HLC exerted the lowest limit of inflammatory reaction and exhibited good histocompatibility. The in vivo histocompatibility of samples was investigated by TEM (Figure 9). After injecting samples for 1 week, in the control group, there are lots of criss-cross collagenous fibers, fibroblasts, and fibrocytes observed in corium layer (Figure 9A). The blank group with secondary electron density homogeneous structure could be seen in the gap. On account of acute inflammatory reaction, a large number of phagocytic cells that could create the phagocytosis
A

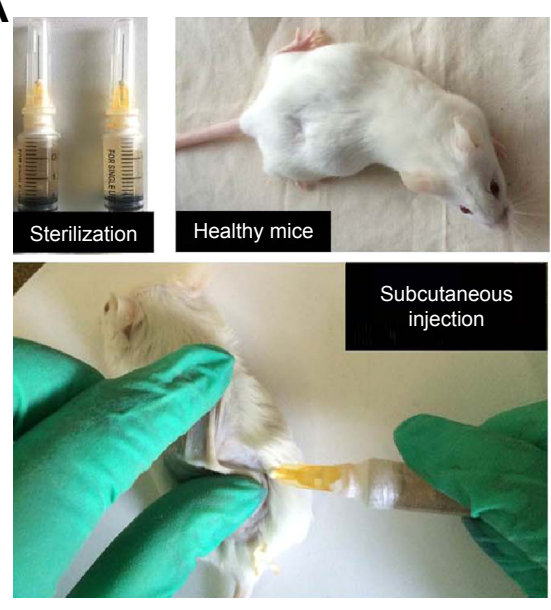

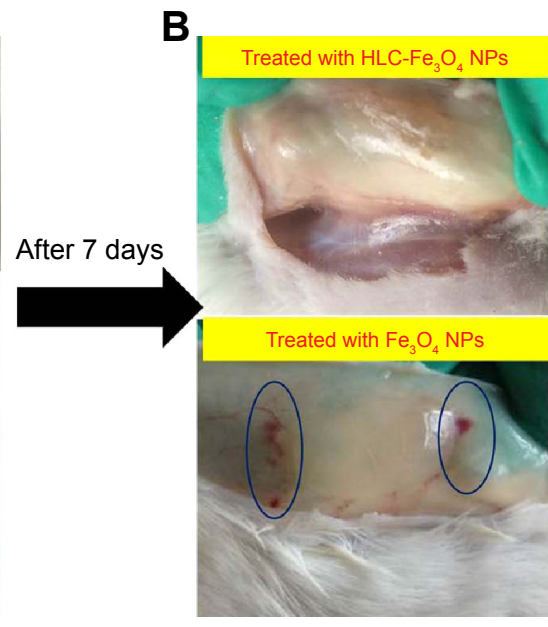

Figure 8 Evaluation of animal histocompatibility in vivo experiments.

Notes: $(\mathbf{A})$ Schematic diagram illustrating the in vivo animal histocompatibility evaluation experiments. (B) The histomorphometry and inflammatory responses of Fe $\mathrm{O}_{4}$ $\mathrm{NPs}$ and $\mathrm{HLC}$-coated $\mathrm{Fe}_{3} \mathrm{O}_{4} \mathrm{NPs}$.

Abbreviations: HLC, human-like collagen; NPs, nanoparticles. 

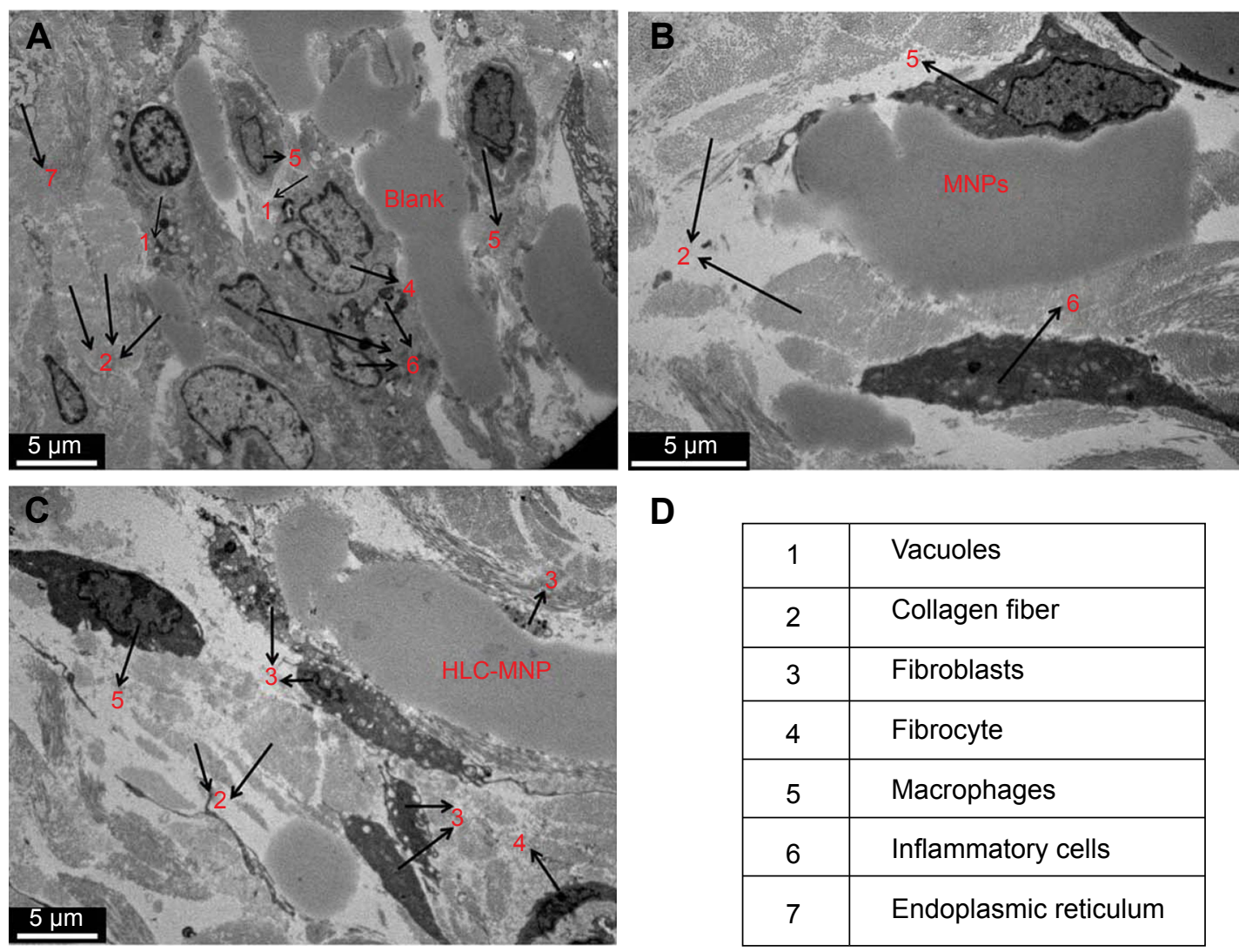

D

\begin{tabular}{|c|l|}
\hline 1 & Vacuoles \\
\hline 2 & Collagen fiber \\
\hline 3 & Fibroblasts \\
\hline 4 & Fibrocyte \\
\hline 5 & Macrophages \\
\hline 6 & Inflammatory cells \\
\hline 7 & Endoplasmic reticulum \\
\hline
\end{tabular}

Figure 9 TEM images of injection samples site surrounding the tissue.

Note: Arrows refer to the cell types in tissue. (A) Blank, (B) MNPs, (C) HLC-MNPs after injection I week, and (D) cell types in tissue.

Abbreviations: HLC, human-like collagen; MNPs, magnetite nanoparticles; TEM, transmission electron microscope.

appeared beside the material. The mitochondria of fibroblast swelled and the mitochondria cristae of the cells dissolved. The vacuolation of mitochondrion and the flat beam expansion of rough surface endoplasmic reticulum could be seen in the TEM. Compared with the blank/negative sample, the $\mathrm{Fe}_{3} \mathrm{O}_{4}$ NPs after coating HLC had irregular shape with electron density homogeneous structure, a large number of collagenous fibers and a small amount of fibroblasts around the material. The injection site of $\mathrm{Fe}_{3} \mathrm{O}_{4} \mathrm{NPs}$ without HLC had a great deal of phagocyte and the endocytosis. The inflammatory cells were much more than these in $\mathrm{HLC}-\mathrm{Fe}_{3} \mathrm{O}_{4} \mathrm{NPs}$, indicating its poor biocompatibility. Therefore, HLC-MNPs exerted the lowest limit of inflammatory reaction and exhibited good histocompatibility. In conclusion, the HLC is the key factor affecting the histocompatibility of the materials, which is able to decrease the inflammatory reaction.

\section{Conclusion}

In summary, a systematic study on the size and surface effects of HLC-coated MNPs on the magnetic hyperthermia heating characteristics and their in vitro/in vivo biocompatibility has been conducted. HLC was employed instead of the commonly used BSA due to its practicality, especially in terms of their low immunogenicity and excellent biocompatibility. The results presented in this study have explicitly shown that the SAR was significantly increased by up to $93 \%$ due to HLC coating. The enhanced SAR after HLC coating is mainly ascribed to enhanced colloidal stability and minimal aggregation. In addition, the significant enhancement of the SAR is favorable for larger NPs. The cell viability studies and in vivo histocompatibility evaluation confirmed that the biocompatibility of MNPs is improved apparently after HLC conjugation. Particularly, $17 \mathrm{~nm}$ HLC-MNPs showed much better biocompatibility compared with its counterpart. After subcutaneous injection of HLC-MNPs into the mice, it was observed that the inflammatory reaction scarcely occurs in the injection site. However, vast phagocyte and endocytosis were presented for the nonconjugated counterparts. As a result, through HLC coating improved biocompatibility and heating enhancement could be achieved by one step. The overall strategy to fabricate HLC-MNPs presented in this study can serve as a general guideline to address the current challenges in clinical magnetic hyperthermia, improved biocompatibility, and enhanced heating characteristics through protein coating, 
enriching the technological application of magnetic hyperthermia agent in clinical applications. Finally, more attention should be dedicated to unravel the effect of specially targeted antibody on the performance of magnetic hyperthermia.

\section{Acknowledgment}

This work was financially supported by the National Natural Science Foundation of China (grant nos 81571809, 21276210, 21476182, and 21176200).

\section{Disclosure}

The authors report no conflicts of interest in this work.

\section{References}

1. Zhao LY, Liu JY, Ouyang WW, et al. Magnetic-mediated hyperthermia for cancer treatment: research progress and clinical trials. Chin Phys B. 2013;22(10): 108104

2. Diederich CJ. Thermal ablation and high-temperature thermal therapy: overview of technology and clinical implementation. Int $J$ Hyperthermia. 2005;21(8):745-753.

3. Seki T, Wakabayashi M, Nakagawa T, et al. Percutaneous microwave coagulation therapy for patients with small hepatocellular carcinoma: comparison with percutaneous ethanol injection therapy. Cancer. 1999;85(8):1694-1702.

4. Vogl TJ, Straub R, Zangos S, Mack MG, Eichler K. MR-guided laserinduced thermotherapy (LITT) of liver tumours: experimental and clinical data. Int J Hyperthermia. 2004;20:713-724.

5. McDannold N, Tempany CM, Fennessy FM, et al. Uterine leiomyomas: MR imaging-based thermometry and thermal dosimetry during focused ultrasound thermal ablation. Radiology. 2006;240(1):263-272.

6. Kohrmann KU, Michel MS, Gaa J, Marlinghaus E, Alken P. High intensity focused ultrasound as noninvasive therapy for multilocal renal cell carcinoma: case study and review of the literature. J Urol. 2002;167(6):2397-2403.

7. Loo C, Lowery A, Halas N, West J, Drezek R. Immunotargeted nanoshells for integrated cancer imaging and therapy. Nano Lett. 2005;5(4): 709-711.

8. Boyer D, Tamarat P, Maali A, Lounis B, Orrit M. Photothermal imaging of nanometer-sized metal particles among scatterers. Science. 2002;297(5584):1160-1163.

9. Gazelle GS, Goldberg SN, Solbiati L, Livraghi T. Tumor ablation with radio-frequency energy. Radiology. 2000;217(3):633-646.

10. Kalambur VS, Longmire EK, Bischof JC. Cellular level loading and heating of superparamagnetic iron oxide nanoparticles. Langmuir. 2007;23(24):12329-12336.

11. Fortin JP, Wilhelm C, Servais J, Ménager C, Bacri JC, Gazeau F. Size-sorted anionic iron oxide nanomagnets as colloidal mediators for magnetic hyperthermia. J Am Chem Soc. 2007;129(9):2628-2635.

12. Jordan A, Scholz R, Wust P, et al. Endocytosis of dextran and silancoated magnetite nanoparticles and the effect of intracellular hyperthermia on human mammary carcinoma cells in vitro. J Magn Magn Mater. 1999;194(1-3):185-196.
13. Mornet S, Vasseur S, Grasset F, Duguet E. Magnetic nanoparticle design for medical diagnosis and therapy. J Mater Chem. 2004;14: 2161-2175.

14. Rosensweig RE. Heating magnetic fluid with alternating magnetic field. J Magn Magn Mater. 2002;252:370-374.

15. Guardia P, Di Corato R, Lartigue L, et al. Water-soluble iron oxide nanocubes with high values of specific absorption rate for cancer cell hyperthermia treatment. ACS Nano. 2012;6:3080-3091.

16. Jang JT, Nah H, Lee JH, Moon SH, Kim MG, Cheon J. Critical enhancements of MRI contrast and hyperthermic effects by dopantcontrolled magnetic nanoparticles. Angew Chem Int Ed Engl. 2009;48: 1234-1238.

17. Lee JH, Jang JT, Choi JS, et al. Exchange-coupled magnetic nanoparticles for efficient heat induction. Nat Nanotechnol. 2011;6:418-422.

18. Liu XL, Yang Y, Ng CT, et al. Magnetic vortex nanorings: a new class of hyperthermia agent for highly efficient in vivo regression of tumors. Adv Mater. 2015;27:1939-1944.

19. Liu XL, Fan HM, Yi JB, et al. Optimization of surface coating on $\mathrm{Fe}_{3} \mathrm{O}_{4}$ nanoparticles for high performance magnetic hyperthermia agents. J Mater Chem. 2012;22:8235-8244.

20. Creixell M, Bohórquez AC, Torres-Lugo M, Rinaldi C. EGFR-targeted magnetic nanoparticle heaters kill cancer cells without a perceptible temperature rise. ACS Nano. 2011;5(9):7124-7129.

21. Samanta B, Yan H, Fischer NO, Shi J, Jerry DJ, Rotello VM. Proteinpassivated $\mathrm{Fe}(3) \mathrm{O}(4)$ nanoparticles: low toxicity and rapid heating for thermal therapy. J Mater Chem. 2008;18(11):1204-1208.

22. Luo YE, Fan DD, Ma XX, Wang DW, Mi Y, Hua XF. Process control for production of human-like collagen in fed-batch culture of Escherichia coli BL 21. Chin J Chem Eng. 2005;13(2):276-279.

23. Liu XL, Zhang H, Chang L, et al. Human-like collagen protein-coated magnetic nanoparticles with high magnetic hyperthermia performance and improved biocompatibility. Nanoscale Res Lett. 2015;10:1-8.

24. Li L, Yang Y, Ding J, Xue J. Synthesis of magnetite nanooctahedra and their magnetic field-induced two-/three-dimensional superstructure. Chem Mater. 2010;22(10):3183-3191.

25. Sun $\mathrm{S}$, Zeng H, Robinson DB, et al. Monodisperse $\mathrm{MFe}_{2} \mathrm{O}_{4}(\mathrm{M}=\mathrm{Fe}$, Co, Mn) nanoparticles. J Am Chem Soc. 2004;126(1):273-279.

26. Víctor M, García B. Monolayers of apolipoproteins at the air/water interface. J Phys Chem B. 2001;105(24):5757-5765.

27. Dzagli MM, Canpean V, Iosin M, Mohou MA, Astilean S. Study of the interaction between $\mathrm{CdSe} / \mathrm{ZnS}$ core-shell quantum dots and bovine serum albumin by spectroscopic techniques. $J$ Photochem Photobiol A. 2010;215(1):118-122.

28. Li R, Nagai Y, Nagai M. Changes of tyrosine and tryptophan residues in human hemoglobin by oxygen binding: near- and far-UV circular dichroism of isolated chains and recombined hemoglobin. J Inorg Biochem. 2000;82(1-4):93-101.

29. Zhu C, Sun Y, Wang Y, Luo Y, Fan D. The preparation and characterization of novel human-like collagen metal chelates. Mater Sci Eng C Mater Biol Appl. 2013;33(5):2611-2619.

30. Yu Y, Fan D. Characterization of the complex of human-like collagen with calcium. Biol Trace Elem Res. 2012;145(1):33-38.

31. Sun JF, Liu X, Chen Y, Zhang Y, Gu N. Exploiting BSA to inhibit the fibrous aggregation of magnetic nanoparticles under an alternating magnetic field. Int J Mol Sci. 2013;14(3):5775-5783.
International Journal of Nanomedicine

\section{Publish your work in this journal}

The International Journal of Nanomedicine is an international, peerreviewed journal focusing on the application of nanotechnology in diagnostics, therapeutics, and drug delivery systems throughou the biomedical field. This journal is indexed on PubMed Central, MedLine, CAS, SciSearch ${ }^{\circledR}$, Current Contents ${ }^{\circledR} /$ Clinical Medicine,

\section{Dovepress}

Journal Citation Reports/Science Edition, EMBase, Scopus and the Elsevier Bibliographic databases. The manuscript management system is completely online and includes a very quick and fair peer-review system, which is all easy to use. Visit http://www.dovepress.com/ testimonials.php to read real quotes from published authors. 